\title{
Pragmatic Functions of Hedges and Politeness Principles
}

\author{
Jingwei TANG (Corresponding author) \\ School of Foreign Languages, Shandong Jiaotong University \\ 5001 Haitang Road, Changqing District, Jinan, 250357, China \\ Tel: 86-158-652-88911 E-mail: jingweitang@126.com
}

Received: 10-04-2013

Accepted: 20-05-2013

Published: 01-07-2013

doi:10.7575/aiac.ijalel.v.2n.4p.155

URL: http://dx.doi.org/10.7575/aiac.ijalel.v.2n.4p.155

\begin{abstract}
Fuzziness is one of the objective characteristics of human language, which makes language flexible and reliable. It's helpful to keep communication more euphemistic and convincing. Hedges are core of fuzzy language and the study on hedges contributes to the understanding of the essence of language. The thesis adopts the theory of face theory and politeness principles and conducts a study on the functions of hedges in communication from the perspective of politeness. The study finds that different types of hedges play the role of maintaining politeness in communication. It is also pointed out that improper use of hedges fails to maintain politeness and leads to pragmatic failure.
\end{abstract}

Keywords: hedges, politeness, face, politeness principles

\section{Introduction}

Language is an important tool to conduct communication and exchange ideas, which has the properties of productivity and simplicity. The productivity of language is in accordance with the diversity of objective things, while its simplicity is in contradiction to the abundance of things. Language needs to break the limitations of notions and express the diversity of things, from which fuzziness of language turns out.

Zadeh(1965) first formulates fuzziness and puts forward the notion of "fuzziness" in his article "fuzzy sets". He also connects fuzziness with language and starts to study fuzziness of language with mathematical methods. The study on fuzziness of language forms a new branch in linguistics-Fuzzy Linguistics. In 1972, Lakoff published his article entitled "Hedges: a Study in Meaning Criteria and the Logic of Fuzzy Concepts", in which "hedges" is firstly coined to refer to the fuzziness of language. Lakoff (1972:471) says, "For me, some of the most interesting questions are raised by the study of words whose meaning implicitly involves fuzziness- words whose job is to make things fuzzier or less fuzzy. I will prefer these words as "hedges."”

Lakoff says (1972:471) “... (for hedges) any adequate treatment will have to take context into account.” Hedges are a group of words whose functions are to conduct communication; the communicative function of words can not work without context. Consequently, the study on hedges should be confined to the range of contexts, from which the pragmatic study on the functions of hedges derives. The thesis tries to explore the pragmatic functions of hedges in politeness.

After Lakoff's study, some researchers have been studying hedges from the perspective of semantics from 1970s and others, instead, focus on the study of the pragmatic functions of hedges from the 1980s. Kasper (1975) analyzes the model verb hedges from the perspective of pragmatics. Brown and Levinson (1978/ 1987) put forward politeness principles and regard hedges as a negative politeness strategy to avoid disagreement. Prince (1982) discusses the categories of hedges and studies hedges as discourse markers. Kasper (1981) finds hedges can help to reduce negative influences and save faces. Some researchers (Blum-kulka, 1984; Gu, 1990...) adopt speech act theory to study hedges. Leech (1984) and Nikula (2000) explore to discuss hedges with the method of discourse analysis. The thesis will focus on the pragmatic functions of hedges and explores their effectiveness to keep politeness.

\section{Classifications of Hedges}

There are different classifications of hedges due to different perspectives of study. The most influential one is put forward by E. F. Prince, J. Frader \& C. Bosk (1982) from the perspective of pragmatics. The pragmatic study on Hedges starts from the 1980s, later than semantic study on hedges. Different from the fuzziness of semantic hedging, pragmatic hedges are not fuzzy themselves. They do not change the apparent meanings of the statement, but reflect the speaker's communicative intent, causing effects of implication. Hedges have a strong pragmatic color, being a wonderful communicative strategy. Hedges can be classified into approximators and shields in the field of pragmatics. Approximators can change peoples' perception on topics of conversations and the original meaning of discourse structure according to the communicative context. That is, approximators can change the true value of discourse, or make a certain degree of amendments based on the given facts, or provide certain range of variation to the original discourse. Approximators can be classified into two subcategories: adaptors (words that make certain amendments to the original meanings of discourse) and rounders (words that provide certain range of variation). Shields don't change the content and true value of discourse, simply conveying speakers' doubt or reservations towards the discourse and 
showing speakers' attitudes indirectly to moderate the tone. As approximators are, shields can be divided into two subcategories: plausibility shields and attribution shields.

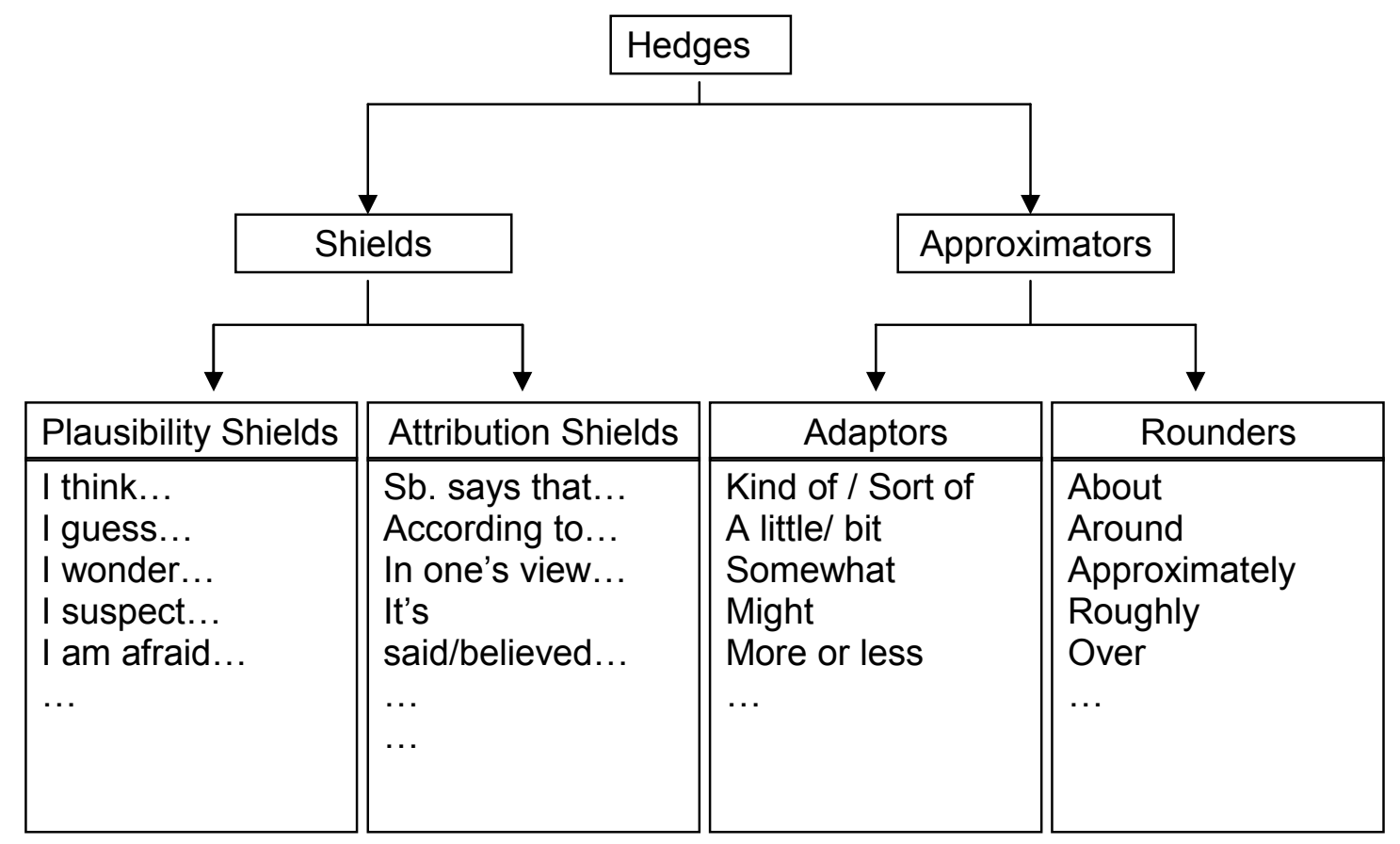

\subsection{Hedges of approximators}

Approximators make certain amendments to the content of the discourse structure or provide the range of adaptation, in other words, approximators are those hedges that can change the original meanings of discourses. Approximators can affect the true value of the discourse, and even cancel the original intent of the discourse. In verbal communication, correct use of these two types of changes can help speakers avoid being assertive, speak appropriately in order to successfully achieve the purpose of communication.

Adaptors usually work as modifiers of terms in communication. More specifically speaking, adaptors are expressions which reveal the degree of truth of the original proposition.

Your attitude is a little rude.

In this sentence, when the speaker criticizes the attitude of the other one, an adaptor "a little" is used, which effectively lessens the degree of criticism and makes it more acceptable to be criticized.

A: What about his ears? Is he still draining fluid?

B: It's just sort of crusted... not really draining.

This is a conversation between a doctor and a patient's parent. If without the approximator "sort of", the doctor's words would sound too arbitrary. "Sort of" helps to make the doctor's description more approximate to the fact and avoid being too arbitrary.

Rounders refer to those hedges which limit the range of subjects. They are usually some words to measure things. When speakers use rounders, they tend to focus only on the size of the range without thinking about the proximity of the subject to the fact, since an exact number is usually mentioned in the discourse and hearers can understand the meanings of discourses in a certain range based on the number. Rounders include: about, approximately, essentially, in most respects, loosely / strictly speaking, something between $\cdots$ and $\cdots$, around, or so, at least, less than, more than $\cdots$

The body temperature is approximately 36.9 centigrade, which is essentially the degree of a healthy condition.

The heart beats eh something between 60 to 64 times a minute.

Such rounders as "approximately" and "something between" are used here since the speaker tries to make sure his words are not too far away from the fact since the speaker can not give an exact number.

\subsection{Hedges of Shields.}

Different from approximators, shields do not change the true value or the original intent of discourse structures. Their functions are to moderate the tone of speakers. Shields work as instructions to indicate the discourse reflecting the speaker's or others' opinions. Hedges of shields can also be subdivided into two subcategories: plausibility shields and attribution shields.

Plausibility shields refer to the speakers' direct speculation of a certain subject or attitudes they hold. In this case, plausibility shields usually include the first person pronouns (singular and plural), which indicates that the speakers are willing to take the responsibility of the truth of their statements or to offer alternative opinions or ideas for reference. Roles of the plausibility shields are to moderate the tone of speakers and avoid imposing their own thoughts on others. 
The experiments are going on smoothly, as far as I know.

As she is not here, I suppose she must have gone home.

In some cases, the tone can also be moderated with some modal verbs indicating speakers' doubt and inference.

The change may be gradual.

I might be able to do that.

Attribution shields do not convey the views or speculation of the speakers, but show the speakers' attitude indirectly by quoting others' perspectives. Common grounds of plausibility shields and attribution shields are that when the speakers put forward a thesis, they can help speakers leave adequate leeway, and mitigate their responsibility for the thesis. The difference between them is that attribution shields usually include some personal structures or the third personal structures, which excludes the speakers, results in an implication of the absence of speakers and protects the face of speakers at the most.

\section{It shows that there was presumably no acute decrease in heart rate.}

Attribution shields in the sentence above help to avoid the personal factors and mitigate the responsibility when speakers try to make statements. The impersonal structure, together with the attribution shields weakens the responsiblity of the speakers when they make statements.

\section{Face Theory and Politeness Principles}

Hedges are often mutually confirmed with pragmatic principles. Exactly speaking, they reflect the speakers' attitude towards the degree of the credibility, details, relevance and clarity of the information provided in the communication.

Brown and Levinson (1987: 59-60) argue that every member of a society has face, which refers to one's public selfimage, and when the speaker decides to commit an act which potentially causes the hearer (or the speaker) to lose face, the speaker will tend to use a politeness strategy in order to mitigate the risk. They think face is "The public self-image that every member wants to claim for himself, consisting of two related aspects:

- negative face: The basic claim to territories, personal preserves, rights to non-distraction---i.e. to freedom of action and freedom from imposition

- positive face: The positive consistent self-image or "personality" (crucially including the desire that this self-image be appreciated and approved of) claimed by interactants."(B \& L, 1987: 61)

Brown and Levinson argue that the factors causing face-threatening involve such variables as "the social distance between the participants, the power that the addressee has over the speaker, and the ranking of the imposition expressed in the utterance in the relevant culture". Brown \& Levinson (1987: 65) suggest some politeness strategies that can minimize the seriousness of a face-threatening act (FTA).

- Bald on-record: These strategies generally do not attempt to mitigate the threat to the hearer's face, although some ways exist to minimize face-threatening acts implicitly.

- Positive politeness: This kind of strategies aims to mitigate the threat to the hearer's positive face. Such strategies are taken to make the hearer feel good about him himself.

- Negative politeness: Negative politeness strategies are conducted to protect the hearer's negative face and focus on avoiding imposing views on the hearer. Negative politeness is an avoidance-based strategy of self-effacement and restraint. Concrete ways to take negative politeness strategies include: being indirect, being pessimistic, minimizing the imposition, and using obviating structures ect.

- Off-record: This strategy uses indirect language and removes the speaker from the potential to be imposing.

There is no difficulty to notice that part of these strategies play similar roles with hedges, especially the negative politeness strategy. That is the very basis of this paper to explore the pragmatic functions of hedges.

Grice's Cooperative Principles (CP) exerts great influence on pragmatic studies. However, there still exist lots of phenomena that CP can't explain. As a remedy for CP, Leech (1983) formulates 'Politeness Principle' (PP), which are presumed to interpret indirect ways to say things and fuzzy ways to express ideas. To Leech, politeness is motivation to do things above. According to Leech (Leech 1983: 133), various politeness strategies are taken to mitigate the facethreatening activities effectively:

- Tact-maxim: Minimize the cost to other; maximize the benefit to other.

- Generosity maxim: Minimize benefit to self, maximize cost to self.

- Approbation maxim: Minimize dispraise of other, maximize praise of other.

- Modesty maxim: Minimize praise of self, maximize dispraise of self.

- Agreement maxim: Minimize disagreement between self and other; maximize agreement between self and other.

- Sympathy maxim: Minimize antipathy between self and other; maximize sympathy between self and other.

\section{Pragmatic Functions of Hedges in Politeness}

Hedges are means of expressing fuzziness. He Z.R. (1985) argues that hedges are characterized by fuzziness, uncertainty and possibility and fuzziness is inexplicitness, which doesn't definitely mean a bad thing. Explicitness isn't 
always in need and it's essential to figure out the implications of words. Without implications, language would be dull. Fuzziness is nature of language, which endows language with various pragmatic functions. Pragmatic study on hedges dates from the middle of 1980s. Many researchers (Fasker, 1975; Brown\& Levinson, 1978\&1987; Prince, 1982; Kasper, 1981) have focused the functions of hedges from the perspective of pragmatics. The thesis aims to explore the pragmatic functions of hedges in the realm of politeness.

\subsection{Approximators and Their Pragmatic Functions in Maintaining Politeness}

In communication, speakers tend to express themselves inexplicitly with hedges on purpose to avoid being assertive and make their words sound more polite. Such hedges as "kind of", "to some extent", "somewhat", "quite", "entirely", "more or less", "really", and "almost" are effective to show politeness to the hearers in conversations.

\section{Our product is quiet cheap.}

"Quite" shows the speaker's basic attitude towards the price of their product, indicating there is little space to concede, while it also tells the hearer there is a degree of flexibility for bargaining. Such an approximator can both make clear the speaker' s idea and leave adequate leeway to the hearer and take the hearer's face into consideration.

\section{Your coat is a little bit dirty.}

To criticize others tends to lead to conflicts and threatens others' face. In this case, certain pragmatic strategy should be taken to mitigate the threatening. "A little" adheres to the principle of "approbation maxim" and shows the speaker's endeavor to reduce the degree of "making others lose face".

\subsection{Rounders and Their Functions in Maintaining Politeness}

Rounders are usually used to refer to the range of variation and to measure things. Speakers adopt rounders with meanings of approximation to offer the range of alternatives. Hearers are supposed to understand the speakers words confined to the range. Rounders usually include: approximately, essentially, about, over, in most respects, roughly, about, ect.

\section{A: What's your annual income? \\ B: Er...well...It's about the expenditure of a new car.}

Obviously, B isn't willing to answer A's question, since it's something private. However, B doesn't intend to make A feel embarrassed by refusing to answer the question and responds to it with fuzziness with the help of "about". B succeeds in making responses to A's question without behaving impolitely.

G. Lakoff (1972) argues that being polite means giving others options; that is, let others make their own decisions and avoid imposing views on others, which is one of the functions of hedges.

Would you like a drink------an orange juice or something?

It's grammatically right if the speaker says, "Would you like an orange juice?" However, such a response might make the hearer feel a bit embarrassed since he has no other options. A sole option seems to be imposed on him. "Something" in the sentence above endows the hearer with more options and makes him feel respected.

\subsection{Plausibility Shields and Their Functions in Maintaining Politeness}

Plausibility shields demonstrate speakers' subjective judgment or the reservations they harbor. Such hedges include: I think, hard to say, as far as I can tell, seem, I wonder, I believe/ assume/ suppose, I'm afraid... When speakers lack enough confidence with the truth of information and dare not to make absolute judgments, they tend to use plausibility shields in order that they can show respect to hearers and in case that they make hearers unpleased.

\section{A: How do you think of my poem?}

$B$ : It's hard to say, I'm not good at literature.

"It's hard to say" helps B avoid making a direct assessment on the poem when B's original judgment is that it's not a good poem. Out of good intentions and politeness, B makes an ambiguous answer with "it's hard to say" and protects A's face. Such an answer also conforms to "approbation maxim" and "agreement maxim" in Leech's politeness principles.

Boss: I'm afraid this is not the first time you are late for work.

Employee: Sorry, I'm ... eh... just a little bit late.

The boss criticizes his employee but with no intention to arouse his internal resistance, so he uses "I'm afraid" to mitigate the criticism to protect the employee's face. In response, the employee uses "a little" to save his own face.

In communication, face needs to be protected on both sides. Each has dual responsibility to maintain face: to protect his face and respect others' face. In reality, there are lots of face threatening acts (FTA). Face is of duality. When a person makes a request, the request is a FTA both to the speaker and to the hearer. In order to be polite and protect the face of the two sides, the request is usually made in a moderate way like in the following sentence.

I wonder whether you can give me a ride.

\subsection{Attribution Shields and Their Functions in Maintaining Politeness}

Attribute shields are often used by speakers to show their speculation or reservation. Speakers tend to quote the 
arguments of the third person and demonstrate their attitudes directly. No matter it is right or wrong, the quotation doesn't necessarily conform to the speaker's own view, having nothing to do with the speaker himself. Even if the quotation is wrong or is against the hearer's view, it wouldn't destroy the communicative relationship of both sides. This is right in accordance to Leech's "Agreement maxim: Minimize disagreement between self and other; maximize agreement between self and other." Speakers use attribution shields to report others' words. Thus no matter the words are right or wrong, they convey the third party's views or attitudes and have nothing to do with the speakers. Even if there is wrong information in these words, it does not influence the relationship between speakers and hearers badly, resulting in maintaining the politeness between them.

According to John, all gentlemen are requested to wear suits on the cocktail party.

Obviously, the speaker wants the hearer to wear suits to attend the party. It's impolite to require the hearer directly and impose requirements on the speaker. "According to John" effectively mitigates the degree of requirement and conveys a clear implication that the hearer should wear suits to the party, which both completes the task of making suggestion and avoids letting the hearer feel embarrassed.

However, roles of hedges are not always positive. Improper use of hedges can cause impoliteness in many cases. It would bring negative consequence to communication. That is, when clear information is in need, hedges should be out of the way. Otherwise, hedges might lead to failure of communication.

\section{A : I'm going to fly to Beijing tomorrow. Will you please tell me what time the flight is?}

B: Maybe it's about ten o'clock?

A is definitely willing to get the exact time of the flight. "Maybe" and "about" fail to provide sufficient and wanted information; this probably results in failure of the conversation and impoliteness. Speakers should take context and hearers into consideration in communication and use hedges properly to avoid pragmatic failure.

Your new dress looks quite beautiful.

"Quite" mitigates the speaker's praise for the dress and violates the principle of "approbation maxim", making the praise sound insincere. Pragmatic failure caused by using hedges improperly is sometimes attributed to the factor of cultural differences. The proper use of certain hedges in the context of English culture may not be applied in another culture.

Guest: Your dishes are so delicious.

Host: Thanks, not bad.

The host's reply is not impolite in English culture when "not bad" is little fuzzy. However, if the context is transferred to Chinese culture, it is an improper reply with some pragmatic failure, since such a reply indicates the host seems not to be a modest man, which does not conform to Chinese custom.

\section{Conclusion}

Hedges are the most typical components of fuzzy language and play roles of maintaining politeness in communication. Hedges can make communication euphemistic, moderate, polite and flexible, which effectively helps to maintain and adjust the relationship between speakers and hearers and keep communication smooth. On the other hand, hedges would make information fuzzy and fail to keep conveyed information appropriate, which may lead to inaccuracy of information. Hedges need to be used timely and moderately in communication.

\section{References}

Blum-kulka, S. (1984)Requests and Apologies: A Cross-cultural Study of Speech Act Realization Patterns. Applied Linguistics, 5, 196:213.

Bunts, L.C. (1991).Vagueness. Kluwer: Academis Publishers.

Brown, P. \& Levinson, S. (1978) 'Universals in language usage: Politeness phenomena', in Goody, E. (ed.), Questions and Politeness: Strategies in Social Interaction ( pp.56 311). England: Cambridge University Press.

Brown, P. and Levinson, S. (1987). Politeness. Cambridge: Cambridge University Press.

Channell, J. (1994). Vague Language. Oxford: Oxford University Press.

Clemen, Gudrun. (1997). "The concept of hedging: Origins, approaches and definitions." In Hartmut Schroeder and Raija Markkanen (eds.), Hedging and Discourse (pp. 98-108).Berlin: de Gruyter.

Fraser, Bruce. (2008). "A brief history of hedging." In Stefan Schneider (ed.), Vagueness in Language. (pp. 87-91). Bingley: Emerald Publishing.

He Z. R.(1985). Hedges and Language Communication. Journal of Foreign Languages, 5, 27-31.

House, J. and Kasper, G. (1981). "Politeness markers in English and in German" In Florian Coulmas (ed.), Conversational Routines (pp.157-185). The Hague: Mouton de Gruyter.

Kasper, B. (1975). Hedged Performatives (A) in Cole P.: Syntax and Semantics Speech Acts (C). New York: Harcont Brace. 
Kasper, G. (1981). Communication Strategies: Modality Reduction. The Interlanguage Bulletins, 4: $266-283$.

Lakoff, George. (1972). "Hedges: a study in meaning criteria and the logic of fuzzy concepts". In P. J. Levi Peranteau \& G. Phares (eds.), Papers from the Eight Regional Meeting. (pp.183-228). Chicago: Chicago Linguistic Society.

Lakoff, Robin. (1973). “The logic of politeness.” In Claudia Corum, T.C. Smith-Stark, \& A. Weiser (eds.) Papers form the Ninth Regional Meeting of the Chicago Linguistic Society (pp. 228-298). Chicago: Chicago Linguistic Society.

Leech, G. (1983). Principles of Pragmatics. London: Longman.

Leech, Geoffrey. (1981). Semantics. Harmondsworth: Penguin.

Leech, Geoffrey. (1983). Principles of Pragmatics. London: Longman.

Levinson, S. C. (1983). Pragmatics. Cambridge: Cambridge University Press.

Prince, E. F. , J. Frader \& C. Bosk. (1982). On hedging in physician-physician discourse. In R. J. Pietro (ed.),Linguistics and the Professions. New Jersey: Ablex, Norwood.

Qin, X. B. (1984). Fuzziness of Language and Language Style of Fuzziness. Journal of Foreign Language, 6, 38-43.

Zadeh, L. A. (1965). 'Fuzz Sets'. In Information and Control (pp. 338-353). New York: Academic Press.

Skehon, H. (1988). The Care and Maintenance of Hedges. ELT Journal, 1, 35-52.

Verchueren, J. (2002). Understanding Pragnmtics. Beijing: Foreign Language Teaching and Research Press.

Wu, T. P. (1999). Fuzzy Language. Shanghai: Shanghai Foreign Language Education Press. 